\title{
The search for excellence in the profession of anesthesiology.
}

\section{María del Carmen Navas-Aparicio*}

Universidad de Costa Rica,Head of the Cleft Lip and Palate-Craniomaxllofacial Unit, Hospital Nacional de Niños, San José, Costa Rica

${ }^{*}$ Correspondence to: Dr. María del Carmen Navas-Aparicio, Professor, Universidad de Costa Rica,Head of the Cleft Lip and Palate-Craniomaxllofacial Unit, Hospital Nacional de Niños, San José, Costa Rica, E-mail: mcnavasaparicio@hotmail.com

Received date: August 21, 2017; Accepted date: August 22, 2017; Published date: August 28, 2017

Citation: del Carmen Navas-Aparicio M. The search for excellence in the profession of anesthesiology. Anaesthesiol Clin Sci Res. 2017;1(1):1-2.

Copyright: (C) 2017 Navas-Aparicio. This is an open-access article distributed under the terms of the Creative Commons Attribution License, which permits unrestricted use, distribution, and reproduction in any medium, provided the original author and source are credited.

\section{Introduction}

Every professional knows the reality of their daily work and the difficulties involved, but must have the ability to look beyond the current moment, must be visionary, to allow him to analyze problems, find solutions and lead to actions to solve them, which implies strengthening the ability to think and relate all the knowledge acquired for permanent professional development, hence I quote the phrase of André Gide, french writer, nobel prize in literature, who said "man cannot discover new oceans unless you have the courage to lose sight of the coast".

Every human being should have access to the newest knowledge and technology [1], so that he can obtain the skills and abilities in his work, which must be of quality [2], to allow him to exchange ideas, to reflect and to have criteria [3], which leads to an approach to other professionals, and consequently to an enrichment of their profession.

The tool exists [2], because the human being has the need to answer many questions and participate in them [4]. Hence, the importance of taking advantage of every opportunity that appears, because the change is daily, and must be able to think and participate in that change and must be able to understand every concept [4].

Learning and transfer of knowledge are cornerstones of the formation of each person; since the first, itself, allows the knowledge to be increased or modified, and the second allows to apply them to different situations daily [4]. But different factors must be considered, such as the personality of this knowledge recipient, the environment and the way in which this transmission and reception of knowledge is carried out, and the need of each individual 3; which means that learning is the walk into the path of knowledge, because an idea is presented to him, which he must assimilate and apply, in order to build and forge his own according to his interest, if he allows an effective process [3].

Medical education is changing rapidly, whether by the change in the health environment and the role of the doctor, new expectations of society, the fast evolution of medical science and the diversity of pedagogical techniques [2]. The future and preparation of each professional depends on each one, who must think and follow the advances of medicine to grow and evolve. The excellence in the profession of anesthesiology can only be defined correctly within the profession itself and this depends on each professional [5].

In recent times, the specialty of Anesthesiology has undergone a transcendental change, not only in clinical practice and research, but also in the technological area as well as the application of the skills in other areas. The professional is part of a multidisciplinary group that requires an exchange of ideas to achieve a common goal, which is the so-called patient [5]. The knowledge advances in a vertiginous way and must be walked daily and in a constant way, to allow the analysis of questions and search for answers in an interactive way, for personal progress and those around him 3, this journal represents what was explained previously, since it allows such exchange of knowledge at all levels of the specialty, between different specialties, either as a reference base or as an interconsulator, which allows for the overcoming and constant individual and professional change, in addition to not only improving knowledge but professional skills that also include skills and attitudes, so it is evident that in the anesthesiologist is explicit four important skills: the understanding of facts, knowledge and understanding of concepts, manual ability and rapid responses [5].

\section{References}

1. García Galisteo E, Del Rosal Samaniego JM, Baena González V, et al. Learning of laparoscopic surgery in Pelvitrainer and in virtual simulators. Actas Urol Esp. 2006;30:451-6.

2. Guzw PA. Using technology to meet the challenges of medical education. Trans Am Clin Climatol Assoc. 2015;126:260-70.

3. Ochoa F, Hacia R. A pedagogy of knowledge. McGrawHill, 1994;167-74. 
Citation: del Carmen Navas-Aparicio M. The search for excellence in the profession of anesthesiology. Anaesthesiol Clin Sci Res 2017;1(1):1-2.

4. Goldin AP, Pedroncini O, Sigman M. Producing or reproducing reasoning? Socratic dialog is very effective, but only for a few. PLoS ONE. 2017;12:e0173584.
5. Smith AF, Greaves JD. Beyond competence: Defining and promoting excellence in anaesthesia. Anaesthesia. 2010;65:184-91. 